REVIEW

\title{
Blood borne infections in sport: risks of transmission, methods of prevention, and recommendations for hepatitis B vaccination
}

\author{
R Kordi, W A Wallace
}

Br J Sports Med 2004;38:678-684. doi: 10.1136/bjsm.2004.011643

\begin{abstract}
Athletes are at risk of blood borne infections through bleeding injuries or injection of drugs with contaminated syringes. Prevention should focus on reducing non-sport associated risky behaviour, as well as dealing appropriately with bleeding injuries. The risk of transmission of hepatitis B virus is particularly high in athletes in contact and collision sports, those who live in or travel to endemic regions, injecting drug abusers, and those who practice first aid when there is no healthcare practitioner available. It is recommended that such athletes, and also adolescent athletes, should be vaccinated against the virus as a routine.
\end{abstract}

See end of article for authors' affiliations

Correspondence to: Dr Kordi, Centre for Sports Medicine, Division of Orthopaedic and Accident Surgery, University of Nottingham, Nottingham NG7 2UH, UK; msxrk@ nottingham.ac.uk

Accepted 4 May 2004
B lood borne infections such as hepatitis B virus (HBV), hepatitis $\mathrm{C}$ virus (HCV), and HIV are all major health problems. According to the World Health Organization (WHO), there are 34-46 million people with HIV world wide, about 5 (4.2-5.8) million of them newly infected. ${ }^{1}$ Approximately 3 (2.53.5) million people died of AIDS in 2003. WHO also reported that "Hepatitis B is one of the major diseases of mankind and is a serious global public health problem". There are more than 350 million people who have chronic, lifelong, infections of HBV world wide. These carriers are at high risk of serious diseases such as liver cirrhosis and primary liver cancer which kill more than one million of them a year. $^{2}$ The American Medical Society for Sports Medicine and the American Orthopaedic Society for Sports Medicine have suggested that these infections are increasing among athletes, and they create important and complex problems for sports medicine practitioners. ${ }^{3}$ News of infected athletes with HIV, especially well known athletes, causes concern among other athletes. ${ }^{4}$

HIV is transmitted through sexual contact, parenteral exposure to blood and blood components, contamination of open wounds or mucous membranes by infected blood, and perinatally from an infected mother to fetus or infant. ${ }^{5}$ Hepatitis B and C are spread through the same routes as HIV. ${ }^{5}$

\section{METHOD}

A search was performed using Medline (19662003) and SPORTDiscus (1949-2001). The search parameters used (including different combinations of the words) were "Blood borne infection", "HIV", "AIDS" and "Hepatitis" and "sport" and "athlete". The reference lists of all relevant articles and reviews were back searched for additional studies. The world wide web, using the Google search engine, was searched using the same key words. Studies with data on possible ways of transmitting blood borne infection in sport and related methods of prevention were reviewed. No study with high quality methodology-for example, randomised clinical trial and cohort-was found. Studies are mainly case reports, the opinion of experts, and consensus statements. Review of these studies suggested that blood borne infections may be transmitted in different situations in different sports and this is discussed below.

\section{POSSIBLE WAYS OF TRANSMISSION IN SPORT}

Bleeding injuries

There is a theoretical risk of blood borne infections being transmitted during sporting activities, from bleeding wounds or exudative skin injury of an infected athlete to the injured skin or mucous membrane of other athletes. It is generally reported that this risk is extremely low. ${ }^{3-8}$

This risk may be higher in contact and collision sports, especially wrestling, boxing, and tae kwon do, because of the higher risk of bleeding injuries and prolonged close body contact. ${ }^{369} 10$ Athletes taking part in these sports should be aware of these small theoretical risks. ${ }^{5}$ Players of basketball, field hockey, ice hockey, judo, soccer, and team handball are at a moderate risk, and those who participate in sports that require little physical contact such as baseball, gymnastics, and tennis are at the lowest risk. ${ }^{5}{ }^{10}$

\section{HIV}

According to researchers in the Centre for Disease Control and Prevention (USA), the risk of transmission of HIV during sports, except boxing, is small-less than one potential

Abbreviations: $\mathrm{HBV}$, hepatitis $B$ virus; $\mathrm{HCV}$, hepatitis $\mathrm{C}$ virus 
transmission in one million games. ${ }^{4}$ This risk is calculated by other researchers to be one transmission in 43 (range 1-85) million games, based on the following factors: $(a)$ the estimated prevalence of HIV among athletes; $(b)$ the risk of percutaneous HIV transmission in health care; (c) the risk of a bleeding injury in American football. ${ }^{11}{ }^{12}$ However, this calculated risk may still be an overestimate because it has been back calculated from the risk through needle stick injuries, and this is probably much greater than the risk resulting from skin injury in sports. ${ }^{12}$

There are no confirmed reports of HIV transmission during sport. $^{359}$ Torre et al $^{13}$ reported one case of seroconversion of HIV as a result of a bleeding injury during a football match in Italy. However, it was later suggested that this report was not sufficiently well documented to confirm that the transmission occurred during sports activity. Transmission in a non-sports setting for this man, who worked in a drug dependency rehabilitation centre, could not be ruled out. ${ }^{38}$

Transmission of HIV during bloody street fights has been reported in the literature. ${ }^{14}{ }^{15}$ Generally, street fist fights can be considered similar to contact sports. However, the manner of physical contact-for example, repeated banging of the forehead of one fighter against the face and forehead of the other in a vigorous street fight-is less likely in typical sports settings.

HIV cannot be transmitted through normal body contact such as touching and sharing sports equipment or using facilities such as locker rooms or bathrooms or contact with contaminated surfaces such as wrestling mats or toilet seats. ${ }^{4}$

\section{HBV}

The concentration of HBV in blood is higher than of HIV, and $\mathrm{HBV}$ is also more stable in the environment. Therefore the risk of transmission of $\mathrm{HBV}$ is $50-100$ times higher than transmission of HIV. ${ }^{8}{ }^{16}$ The estimated risk of transmission of blood borne infections after percutaneous exposure in healthcare workers is calculated to be $0.2-0.5 \%$ for HIV, $2-40 \%$ for HBV, and $1.8-10 \%$ for HCV. ${ }^{17}{ }^{18} \mathrm{HBV}$ is resistant to drying, ambient temperatures, simple detergents, and alcohol and can be stable on environmental surfaces for at least seven days. ${ }^{217}$ Hence transmission of HBV can occur via inanimate objects-for example, environmental surfaces. ${ }^{17}$ Therefore the risk of HBV transmission in sport is probably greater than that of other blood borne infections.

The theoretical risk of transmission of $\mathrm{HBV}$ in sport (calculated using the same methods as used for $\mathrm{HIV}^{11}{ }^{12}$ ) is between one transmission in every 850000 to 4.25 million games and one transmission in 10 000-50 000 games. ${ }^{12}$ The range of these theoretical risks is wide, but they do give an indication of the risk of transmission in sport. As an example, in 1995-1996, about 800000 high school boys participated in American football ( $17 \%$ of all school athletes). ${ }^{19}$ If every footballer had an average of three training sessions a week and had 10 months training a year, their risk would be calculated as between 68 (range 23-113) and 5760 (range 1920-9600) transmissions in 1995. In 1995, it was estimated that 400 new occupational HBV infections occurred in US healthcare workers. This has decreased from 17000 in 1983 because of the implementation of standard precautions and vaccination. ${ }^{17} 20$ Therefore, theoretically, the numbers of potential transmitted cases of HBV in sport are significantly higher than those now occurring in health care, presumably because of a lack of prophylaxis in sport.

Two papers, both from Japan, report HBV transmission in sport. ${ }^{21}{ }^{22}$ Kashiwagi et al ${ }^{22}$ reported an outbreak of hepatitis B infection in a high school sumo wrestling club. Five of 10 members of the club developed hepatitis B during one year. The authors identified an asymptomatic HBV antigen-e positive carrier as the source of infection. They suggested that HBV was transmitted from the carrier to the others through skin cuts and abrasions caused by wrestling. Wrestlers in that club were known to continue to wrestle even when they were injured and bleeding from skin wounds.

More recently, Tobe et $a l^{21}$ reported an outbreak of HBV among members of a university American football team. They detected 11 cases of HBV infection (five of acute hepatitis and six of subclinical infection) among 65 members of the team over a period of 19 months. For these student footballers, the incidence of $\mathrm{HBV}$ infection was $20 \%$, which was significantly higher than the $1.8 \%$ recorded for a comparison group of non-footballing students $(\mathrm{p}<0.01)$. The authors found a carrier of HBV as the source of transmission and suggested that transmission had probably occurred as a result of contact with open wounds of the carrier during sporting activity.

Ringertz and Zetterberg ${ }^{23}$ reported an outbreak of 568 cases of HBV infection among Swedish cross country track finders during 1957-1963. They believed that the transmission had occurred through skin lesions mainly during washing after the competition. Over $95 \%$ of track finders had scratches and skin lacerations. They reported that the epidemic was brought to an end when adequate protective clothing was made a compulsory regulation. However, this regulation was abolished when another smaller outbreak occurred in 1965-1966 among track finders who wore the appropriate protective clothing. ${ }^{23}$

One epidemiological study evaluated the prevalence of HBV infection among athletes. Siebert et $a l^{24}$ evaluated the prevalence of markers of past hepatitis $\mathrm{B}$ infection in footballers in South Australia. The prevalence was not different from blood donors of the same age. The prevalence of chronic HBV in South Australia is reported to be very low at $0.16 \%{ }^{24}$

Table 1 Epidemiology of hepatitis B and vaccination strategies ${ }^{2} 4647$

\begin{tabular}{|c|c|c|c|c|}
\hline Endemicity* & $\begin{array}{l}\% \text { of carriers in } \\
\text { population }\end{array}$ & $\begin{array}{l}\% \text { of infected } \\
\text { population }\end{array}$ & Age of infection & Strategy for vaccination \\
\hline High & $>8(8-20)$ & $70-90<$ the age of 40 & $\begin{array}{l}\text { Mostly perinatal and childhood } \\
\text { periodt }\end{array}$ & Universal infant and high risk group \\
\hline $\begin{array}{l}\text { Intermediate } \\
\text { Low }\end{array}$ & $\begin{array}{l}2-8 \\
<2\end{array}$ & $\begin{array}{l}20-70 \\
<20\end{array}$ & $\begin{array}{l}\text { Both childhood and adult } \neq \\
\text { Mostly high risk adolescents and } \\
\text { adults } \S \text {, }\end{array}$ & $\begin{array}{l}\text { Universal infant and high risk group } \\
\text { Universal infant or adolescent and/or } \\
\text { high risk group }\end{array}$ \\
\hline
\end{tabular}

*Endemic: prevalent continuously to some degree in a community or region.

†ln children, infection is rarely acute with $25-90 \%$ becoming chronic carriers.

fln adults, infection is often acute with 5-10\% becoming chronic carriers.

$\S$ High risk groups such as sexual/household contacts of infected person, healthcare workers, injection drug users, those receiving non-sterile acupuncture or tattooing, homosexual and active heterosexual men.

$\uparrow 30 \%$ of those with acute infection do not have identifiable risk factors. 


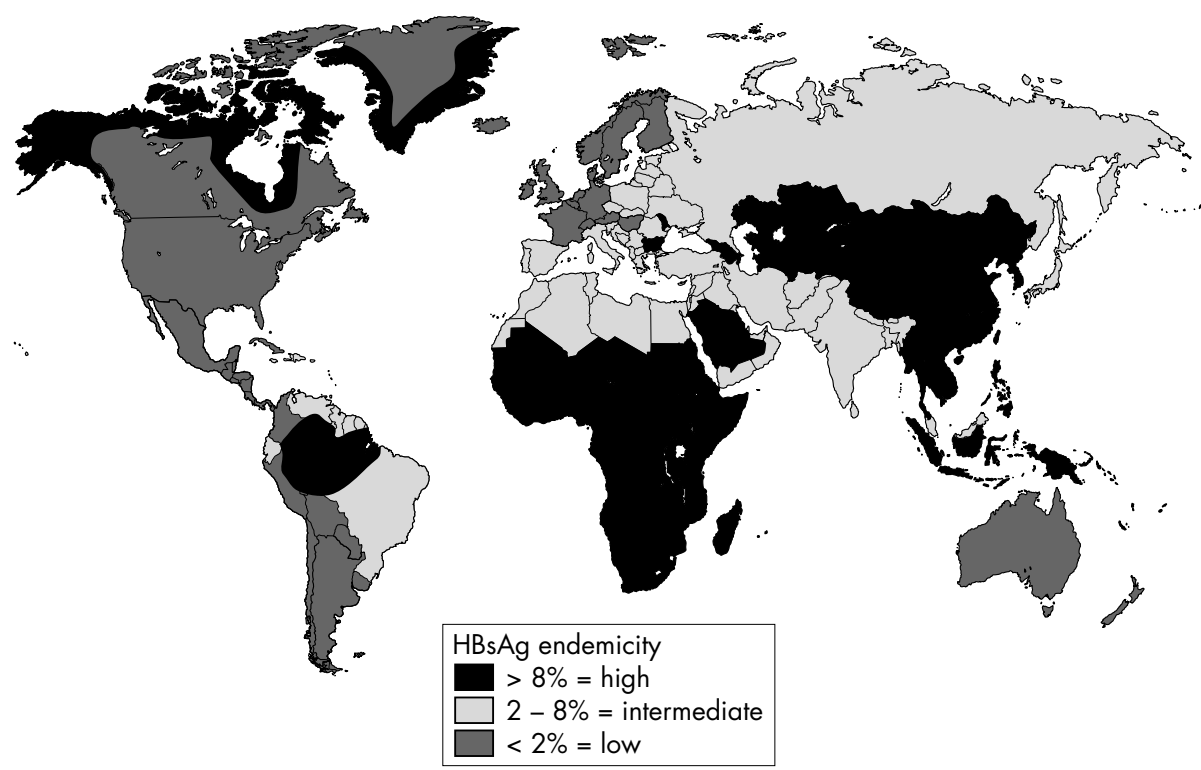

Figure 1 Geographic pattern of hepatitis B prevalence, 1997. Taken with permission from Introduction of hepatitis B vaccine into childhood immunization services. Geneva: WHO, 2001; WHO/V\&B/01.31; data as of 6 April 1998. Endemic: prevalent continuously to some degree in a community or region.

It has been suggested that blood borne infections may be transmitted through sharing a water container, because bleeding around the mouth is common in contact sport. ${ }^{25}$ Therefore it is now recommended that water containers should be available individually for each player in contact sports. Athletes should use squeeze water bottles which they do not put in their mouth.

\section{Doping and drug abuse}

Blood borne infections can be transmitted through blood doping. There is also a risk from sharing needles which may be associated with drug abuse in sport. Injectable drugs used in sports include steroids, hormones, and vitamins. ${ }^{4}$

Three separate cases of HIV infection associated with sharing needles among bodybuilders have been reported, two in the United States and one in France. ${ }^{26-28}$ In one of the cases, there was simultaneous infection with HBV. ${ }^{27}$ In none of the cases was there a history of participation in any other risky behaviour. One case of hepatitis $\mathrm{C}$ infection has been reported as a result of a recreational weightlifter sharing needles to inject anabolic androgenic steroid. ${ }^{29}$

Parana $e t ~ a l^{30}$ reported three soccer players from one amateur club who were infected with HCV as a result of sharing a syringe to inject intravenous vitamin complexes. They suggested that during the 1970s and 1980s intravenous vitamin complexes were abused by many athletes in Brazil. Syringes have often been shared by athletes who inject vitamins minutes before a game. ${ }^{30}$

A 1993 study estimated that, in the United States, there were one million people who were either current or past users of anabolic androgenic steroids. ${ }^{31}$ Of these, $50 \%$ were intramuscular drug users, and about $25 \%$ had shared needles. ${ }^{32}$ Therefore it seems that the risk of transmission in this way may be considerable among athletes, especially bodybuilders.

\section{Sexual activity}

Blood borne infections can be transmitted through sexual activity. Having homosexual sex with men and having multiple partners are the most significant risk factors for these infections. However, the most common method of transmission of HBV during adulthood is heterosexual contact with an infected individual (because this exposure occurs most commonly), followed by injected drug abuse, and then homosexual contact. ${ }^{33}{ }^{34}$ There is no firm evidence that transmission of blood borne infections among athletes through sexual activity is more common than for the general population. There is limited literature in this controversial area. Some studies have suggested that some high risk sexual activities may be more common among male athletes than non-athletes, and athletes may perform more sexual activity, ${ }^{35}$ less safe sex, ${ }^{36}$ have a greater prevalence of sexually transmitted diseases, ${ }^{37}$ and have a greater number of sexual partners. $^{36}{ }^{37}$ Other studies, mainly on high school sports participants, did not show significant differences among male athletes and non-athletes with regard to their level of sexual activity ${ }^{38-40}$ and number of sex partners. ${ }^{38-40}$ One study $^{38}$ reported that white male and female athletes have fewer multiple partners than the non-athlete, but African American male athletes have more multiple partners than their comparative non-athlete group. There is some evidence that sexual activity ${ }^{35}{ }^{38-41}$ and having multiple partners ${ }^{38-40}$ are less common among female high school athletes than nonathletes.

\section{Travelling}

According to WHO, "living in regions or travelling to regions with endemic hepatitis are risk factors for the HBV infection." ${ }^{\prime \prime 3}$ Some athletes, especially at the professional levels, travel regularly to different areas of the world; therefore these groups of athletes may be at an even higher risk.

\section{Lack of trained healthcare providers}

Healthcare professionals in sport such as first aid providers and team doctors are at particular risk of blood borne infections because they treat bleeding injuries. During sports training sessions in developing countries, there may be no healthcare professional available, as was typically the situation in the United Kingdom in the past for less professional teams and clubs, where coaches and/or other athletes have routinely performed first aid treatment. In such situations, coaches and athletes are at risk of blood borne infections in the same way as healthcare professionals. Moreover, they may be at more risk because of their more 
limited knowledge and skills. Bourliere et al ${ }^{42}$ reported a case of hepatitis $\mathrm{C}$ infection as a result of sharing a handkerchief to dry bleeding wounds after a bloody fisticuffs. This example of transmission could occur in the sports setting when the first aider is not an "expert". Therefore all coaches and athletes should be educated about first aid, infection control, and hygiene.

\section{PREVENTION}

The following position statements and recommendations on blood borne infections and sports have been documented in the literature (see the web site references):

- Position statement of the American Academy of Pediatrics on "Human immunodeficiency virus and other bloodborne viral pathogens in the athletic setting" (1999). ${ }^{6}$

- Position statement of the Canadian Academy of Sport Medicine on "HIV as it relates to sport" (1999).

- Consensus statement of the International Federation of Sports Medicine $e^{5}$ and WHO on "AIDS and sports" (1997). This is based on the Joint position statement of American Medical Society for Sports Medicine and the American Orthopaedic Society for Sports Medicine.

- Policy statement of Sports Medicine Australia on "infectious diseases with particular reference to HIV (AIDS) and viral hepatitis (B, C, etc)" (1997). ${ }^{25}$

- Joint position statement of the American Medical Society for Sports Medicine and the American Orthopaedic Society for Sports Medicine on "Human immunodeficiency virus (HIV) and other blood-borne pathogens in sports."'3

It is highlighted that the main methods of transmission of blood borne infections in athletes are not through sports activity, but are similar to those for the general populationfor example, unsafe sexual activity and sharing needles. ${ }^{3}{ }^{4}$ Therefore efforts to prevent these infections among athletes should also be focused on the prevention of these "nonsporting" methods. ${ }^{8} 9$

\section{"Education is the most important task in prevention"}

The theoretical risk of blood borne infection in sport is from contact with blood, body fluids, and other fluids containing blood. Therefore prevention in sport should focus on the most appropriate way to deal with bleeding injuries and related hygiene, summarised in the following. ${ }^{35}$

- Prompt and appropriate treatment of bleeding sports injuries

- Using proper equipment-for example, gloves

- Cleaning the blood from wounds with soap and water or an antiseptic

- Removing athletes with bleeding injury, not minor cuts or abrasions, from event as soon as possible

- Prompt changing of blood soaked uniforms

- Any skin injuries acute or chronic-for example, abrasions, cuts, or oozing wounds-should be covered during sports activities with an occlusive dressing until complete healing has taken place.

- All wounds and injuries should be promptly detected and reported by athletes and coaches

- Appropriate protective equipment should be used at all times by athletes, including mouth protectors, in contact sports
- The healthcare provider must follow the guidelines provided by WHO as universal precautions (see http:// www.who.int/hiv/topics/precautions/universal/en/)

- Any equipment contaminated with blood should be removed from the sports activity area; if this is not possible-for example, a wrestling mat - the item must be cleaned and dried appropriately (using disposable cloths and a fresh solution of one part household bleach to ten parts water).

Education is the most important task in prevention. Athletes, their families, healthcare providers, coaches, officials, and others involved in sports should be educated. ${ }^{359}$

\section{Testing}

The recommendations for testing of blood borne infections in athletes are as follow.

- Mandatory: Mandatory testing or widespread screening of athletes for blood borne diseases is not recommended because these tests could not be used effectively for prevention, the costs would be excessive, and there are additional legal and ethical issues. ${ }^{37}$ However, some athletic organisations, such as the International Federation of Associated Wrestling Styles and the International Boxing Federation, have now ordained that the AIDS detection test should be compulsory for participants in their sports. In addition, the International Amateur Boxing Association has recently recommended that an HIV test should be carried out in pre-participation physical examinations. ${ }^{4} 4344$

- Voluntary: voluntary testing should be recommended for all high risk athletes in the same way as for non-athletesfor example, if they have multiple sexual partners, inject drugs (including drugs of abuse and doping with ergogenic aids), or have sexual contact with at risk persons. $^{3}$

\section{Vaccination}

$\mathrm{HBV}$ infection can be prevented by vaccination, which is safe and $95 \%$ effective. ${ }^{25}$ Different immunisation strategies have been recommended for different regions of the world because of the different epidemiological patterns of HBV infection (table 1, fig 1). WHO has recommended that all countries should integrate hepatitis $\mathrm{B}$ vaccination into their national immunisation programmes since $1992 .^{2}$

Athletes have not yet been categorised as a high risk group "to be vaccinated". The International Federation of Sports Medicine and WHO do not recommend immunisation against HBV for athletes. ${ }^{5}$ There is no clear evidence on the magnitude and the exact risk of transmission of $\mathrm{HBV}$ in sport. However, this review of current studies suggests that the following groups of athletes are at significant risk and should now be recommended to receive hepatitis B vaccine.

- Non-infected athletes living in regions with endemic hepatitis B

- Athletes who live in low endemic region but regularly travel to regions of high endemicity

- Athletes who practice first aid in the absence of healthcare providers, including coaches

- Athletes suspected of doping (injecting drug abusers)

- Athletes who have other risk factors (table 1)

- Participants in contact and collision sports such as wrestling and boxing 
Some influential groups, such as Sports Medicine Australia, have strongly recommended that "all participants involved in contact/collision sports and playing under adult rules be vaccinated against hepatitis $\mathrm{B}^{\prime \prime}$, and the American College Health Association has recommended hepatitis B immunisation for all student athletes since 1994. ${ }^{9}$

Most HBV infections in the low endemicity regions occur in young adults. ${ }^{33}$ Adolescent vaccination could protect nonvaccinated children before they enter this high risk period. The American Academy of Pediatrics has recommended that all children and adolescents should be immunised against HBV, ${ }^{6}$ a recommendation that has received wide support. ${ }^{8} 48$ The non-vaccinated adolescent athletes should be recommended to be vaccinated against HBV

The cost of vaccination might have been a real problem for the immunisation of athletes in the past..$^{49}$ However, the cost of HBV vaccine has dramatically decreased, and it has been shown that global HBV vaccination is cost effective for large populations, ${ }^{47} 50$

The strategy of vaccinating groups considered to be at high risk of contracting hepatitis $\mathrm{B}$ has not been successful in significantly reducing the incidence of new infections. This may be because of difficulties in identifying and approaching high risk groups, lack of compliance, participation in high risk behaviour before identification, and lack of recognised risk factors in some infected people. ${ }^{51}$ Therefore universal vaccination of children and adolescents before the age of 13 has been recommended..$^{33}$

\section{Infected athletes}

It seems that moderate intensity exercise is not harmful to the patient with HIV. ${ }^{35}$ There is some evidence that moderate exercise may have some psychological and immunological benefits, especially for the patient with HIV. ${ }^{3}$

HIV infection alone is not a reason to prevent athletes from continuing with their sports activities. ${ }^{3-7}$ However, the decision to take part in sport at a highly competitive level should be down to the individual, based on factors such as the state of health of the athlete, the HIV status, the risk of infection transmission, and the level of psychological and physical stress of the sport. ${ }^{35}$ There are no studies on the effect of strenuous exercise on the HIV positive athlete in the literature. However, it has been shown that very strenuous exercise has some suppressive effects on the immune system of healthy athletes, which does need to be considered. ${ }^{52}$

There is no evidence that high level competitive sports activity is a problem for asymptomatic HBV carriers. ${ }^{3-7}$ In the case of acute HBV infection, return to sporting activity should be made on the basis of clinical signs and symptoms such as fever, fatigue, and hepatomegaly.

The risk of transmission from athletes infected with HIV, $\mathrm{HBV}$, or HCV to other athletes is very low; therefore, on the basis of risk of infection, most athletes with these viral infections should be allowed to participate in all sports $^{6}$ with the main emphasis being placed on preventive activities.

\section{CONCLUSIONS}

There is a small risk of transmission of blood borne infections in athletes through bleeding injuries or injecting (as in drug abuse). Prevention should focus on non-sporting risky behaviours. In the sport setting, prevention should be mainly related to the most appropriate way of dealing with bleeding injuries. The risk of HBV transmission is higher than other blood borne infections in sports. Some groups of athletes are at more risk of HBV infection, such as participants in contact and collision sports, athletes who live in or travel to highly endemic regions, and injecting drug abusers. It seems
What is already known on this topic

There is a real risk of transmission of blood borne infections in athletes as a result of bleeding injuries and sharing needles for those who inject drugs. Some preventive recommendations have been published in this field.

\section{What this study adds}

This study reviews the different ways of transmitting blood borne infections in sport and attempts to quantify the risks based on the limited scientific evidence available. It summarises the preventive recommendations, and vaccination against hepatitis $B$ is strongly recommended for many current athletes.

that vaccination against HBV should be recommended for these athletes, as well as for adolescent athletes. However, the small number of studies published in this field are mainly case reports, and more research in this area is needed.

\section{Authors' affiliations}

R Kordi, Sports Medicine Centre, Tehran University of Medical Sciences, Tehran, Iran

W A Wallace, Centre for Sports Medicine, Division of Orthopaedic and Accident Surgery, University of Nottingham, Nottingham, UK

Conflict of interest: none declared

\section{REFERENCES}

1 World Health Organization (2003). HIV/AIDS (online). www.who.int/hiv/ en/ (accessed 28 Nov 2003).

2 World Health Organization (2000). Hepatitis B (online). www.who.int/inf-fs/ en/fact204.html (accessed 28 Nov 2003).

3 The American Medical Society for Sports Medicine and the American Orthopaedic Society for Sports Medicine (1995). Human Immunodeficiency virus (HIV) and other blood-borne pathogens in sports, Joint Position Statement (online). www.amssm.org/hiv.html (accessed 25 Nov 2003).

4 Centers for Disease Control and Prevention, National prevention information network (1996). HIV/AIDS and Sports (online) www.ed.state.nh.us/HealthHIVAIDS/HIVPolicy TrainingResourcespdf (accessed 25 Nov 2003).

5 International Federation of Sports Medicine (1997). AIDS and sports, FIMS Position Statement (online). www.fims.org/fims/frames.asp (accessed $25 \mathrm{Nov}$ 2003).

6 American Academy of Pediatrics. Human immunodeficiency virus and other blood-borne viral pathogens in the athletic setting. Pediatrics 1999; 104: 1400-3.

7 Robinson J. The Canadian Academy of Sport Medicine (1999). Position statement, HIV as it relates to sport (online). www.casm-acms.org/ (accessed 18 Nov 2003).

8 Mast EE, Goodman RA, Bond WW, et al. Transmission of blood-borne pathogens during sports: risk and prevention. Ann Intern Med 1995; 122:283-5.

9 The National Collegiate Athletic Association (2003). 2003-04 NCAA Sports Medicine Handbook (online) www.ncaa.org/library/sports sciences/sports_med_handbook/2003-04/indexhtml laccessed 18 Nov 2003).

10 Goldsmith $M$. When sports and HIV share the bill. Smart money goes on common sense. JAMA 1992;267:1311-14.

11 Brown LS, Drotman DP, Chu A, et al. Bleeding injuries in professional football. Estimating the risk for HIV transmission. Ann Intern Med 1995; 122:271-4.

12 McGrew CA. Blood-borne pathogens and sports. In: Fields KB, Fricker PA, eds. Medical problems in athletes. Oxford: Blackwell Science, 1997:64-9.

13 Torre D, Sampietro C, Ferraro G, et al. Transmission of HIV-1 infection via sports injury. Lancet 1990;335:1105.

14 O'Farrell N, Tovey SJ, Morgan-Capner P. Transmission of HIV-1 infection after a fight. Lancet 1992;339:246.

15 Ippolito G, Del Poggio P, Arici C, et al. Transmission of zidovudine-resistant HIV during a bloody fight. JAMA 1994;272:433-4. 
16 World Health Organization (2000). Hepatitis B, fact sheet (online) www.who.int/inf-fs/en/fact204.html (accessed 28 Nov 2003).

17 Beltrami EM, Williams IT, Shapiro CN, et al. Risk and management of bloodborne infections in health care workers. Clin Microbiol Rev 2000;13:385-407.

18 Gerberding JL. Management of occupational exposures to blood-borne viruses. N Engl J Med 1995;332:444-51.

19 National Federation of State High School Associations (2003). Rate of participation in high school sports vs. total enrolment (online). www.nfhs.org/ Participation/2003/2002_2003_Participation_Summa rypdf (accessed 2 Dec 2003).

20 International health care worker safety centre, University of Virginia. (2001). Risk of infection following a single HIV, HBV, or HCV-contaminated needlestick or sharp instrument injury (online). www.med.virginia.edu/ medcntr/centers/epinet/estimates.html (accessed 5 Dec 2003).

21 Tobe K, Matsuura K, Ogura T, et al. Horizontal transmission of hepatitis B virus among players of an American football team. Arch Intern Med 2000;160:2541-5

22 Kashiwagi S, Hayashi J, Ikematsu $\mathrm{H}$, et al. An outbreak of hepatitis B in members of a high school sumo wrestling club. JAMA 1982;248:213-14.

23 Ringertz O, Zetterberg B. Serum hepatitis among Swedish track finders. An epidemiologic study. N Engl J Med 1967;276:540-6.

24 Siebert DJ, Lindschau PB, Burrell CJ. Lack of evidence for significant hepatitis B transmission in Australian Rules footballers. Med J Aust 1995: 162:312-13.

25 Sports Medicine Australia (1997). Policy on infectious diseases with particular reference to HIV (AIDS) and viral hepatitis (B, C, etc) (online). www.sma.org.au/information/ssdataintro.asp (accessed 5 Nov 2003).

26 Henrion R, Mandelbrot L, Delfieu D. HIV contamination after injections of anabolic steroids. Presse Med 1992;8:218.

27 Sklarek HM, Mantovani RP, Erens E, et al. AIDS in a bodybuilder using anabolic steroids. N Engl J Med 1984;311:1701.

28 Scott MJ, Scott MJJ. HIV infection associated with injections of anabolic steroids. JAMA 1989;14:207-8.

29 Rich JD, Dickinson BP, Merriman NA, et al. Hepatitis C virus infection related to anabolic-androgenic steroid injection in a recreational weight lifter. Am J Gastroenterol 1998;93:1598.

30 Parana R, Lyra L, Trepo C. Intravenous vitamin complexes used in sporting activities and transmission of HCV in Brazil. Am J Gastroenterol 1999;94:857-8.

31 Yesalis CE, Kennedy NJ, Kopstein AN, et al. Anabolic-androgenic steroid use in the United States. JAMA 1993;8:1217-21.

32 Dickinson BP, Mylonakis E, Strong LL, et al. Potential infections related to anabolic steroid injection in young adolescents. Pediatrics 1999; 103:694.

33 World Health Organization (2002). Hepatitis B (online). www.who.int/emcdocuments/hepatitis/docs/whocdscsrlyo20022/index.html (accessed 11 Dec 2003).

34 Harrington DW. Viral hepatitis and exercise. Med Sci Sports Exerc 2000;32(suppl 7):S422-30.

35 Trost SG, Levin S, Pate RR. Sport, physical activity and other health behaviours in children and adolescents. In: Armstrong N, Van Mechelen W, eds. Paediatric exercise science and medicine. Oxford: Oxford University Press, 2000:295-310

36 Nattiv A, Puffer JC, Green GA. Lifestyles and health risks of collegiate athletes: a multi-center study. Clin J Sport Med 1997;7:262-72.

37 Nattiv A, Puffer JC. Lifestyles and health risks of collegiate athletes. J Fam Pract 1991;33:585-90.

38 Pate RR, Trost SG, Levin S, et al. Sports participation and health-related behaviors among US youth. Arch Pediatr Adolesc Med 2000;154:904-11.

39 Kulig K, Brener ND, McManus T. Sexual activity and substance use among adolescents by category of physical activity plus team sports participation. Arch Pediatr Adolesc Med 2003;157:905-12

40 Miller KE, Sabo DF, Farrell MP, et al. Athletic participation and sexual behavior in adolescents: the different worlds of boys and girls. J Health Soc Behav 1998;39:108-23.

41 Sabo DF, Miller KE, Farrell MP, et al. High school athletic participation, sexual behavior and adolescent pregnancy: a regional study. J Adolesc Health 1999;25:207-16.

42 Bourliere $M$, Halfon $P$, Quentin $Y$, et al. Covert transmission of hepatitis $C$ virus during bloody fisticuffs. Gastroenterology 2000;1 19:507-11.

43 International Federation of Associated Wrestling Styles (2003). Health regulations (online). www.fila-wrestling.com/beta/presse/officiels/REGLTSAN-A-PDF.pdf (accessed 3 Nov 2003).

44 Medical Commission of the International amateur Boxing association (2000). Medical handbook of amateur boxing (online). www.aiba.net/ pressreleases/medicalreleses/Medical_release 1.html (accessed 9 Dec 2003)

45 Dittmann S. Special address: safety of hepatitis B vaccination. Vaccine 2000;18(suppl 1):S10-11.

46 The Immunization Practices Advisory Committee. Hepatitis B virus: a comprehensive strategy for eliminating transmission in the United States; through universal childhood vaccination: recommendations of the Immunization Practices Advisory Committee (ACIP). Morb Mortal Wkly Rep 1991;40(RR-13):1-19.

47 World Health Organization (1996). Hepatitis B, vaccines, immunization and biologicals (online). www.who.int/ > (accessed 2 Oct 2003).

48 Strikas RA, Schmidt JV, Weaver DL, Wolfe CR. Immunizations recommendations and resources for active patients. Phys Sportsmed (online) $2001 ; 29(10)$. www.physsportsmed.com/ (accessed 10 Nov 2003).
49 Potera C. The sports physical: a good time for 'Hep B' shots? Phys Sportsmed (online). 1996;24(8). www.physsportsmed.com/ (accessed 10 Nov 2003).

50 Van Damme $P$, Kane $M$, Mehens A. Integration of hepatitis $B$ vaccination into national immunisation programmes. BMJ 1997;314:1033-6.

51 Dobson S, Scheifele D, Bell A. Assessment of a universal, school-based hepatitis B vaccination program. JAMA 1995; 18:1209-13.

52 Mackinnon LT. Chronic exercise training effects on immune function. Med Sci Sports Exerc 2000;32(suppl 7):S369-76.

\section{COMMENTARY}

This paper is a good review of what is known about the topic in question, and presents viewpoints that are consistent with most experts in the field. In my opinion (which dissented from the other reviewers of this paper), there is not a sufficient highlight of not only the current lack of scientific knowledge in this field, but also the difficulty in obtaining the knowledge we would like to have. The hard questions in this field are: (1) what is the real risk of transmission in a contact sport that an infected athlete poses to teammates and opponents? (2) Is this risk sufficient to justify mandatory notification to other players and/or exclusion?

Calculations for risk of transmission in sport (which are reported in this review to be less than one in a million) are presented based on the randomly selected athlete. It should be noted that the risk of transmission (both theoretical and actual) becomes considerably higher when it is known that at least one athlete on the field is HIV or hepatitis positive. The risk of transmission does not need to be divided by the prevalence of these diseases in the population in this scenario.

The authors reject the report of Torre et al of sporting transmission of HIV based on arguments previously published. However, although this is not a proven case of sporting transmission, it remains a possible one. The burden of proof may be impossibly high with respect to sporting transmissions. In a hospital, whenever there is a needlestick injury, an incident report is filed and blood is immediately taken from the patient and injured staff member. This does not happen in sport. It is rare for blood/blood contacts to be recorded in injury surveillance systems, and there is no expectation that competitors will undergo blood tests after matches if contact has occurred. Therefore, even if an HIV transmission did occur during a sporting activity, it is likely that this would be either missed or considered not proven, even if suspected. Based on current expert opinion, many athletes would have at least one risk factor in their personal sexual or other history that would be considered more likely to be the source of their infection than a bloody collision they had suffered on the sporting field.

Because immunisation for hepatitis B is available, a notification and/or exclusion policy for this disease is probably not justified, although it presents a difficult dilemma for potential opponents who have attempted immunisation but who do not seroconvert. I would suggest that athletes infected with hepatitis C or HIV who wish to continue playing contact sports present a dilemma that even the most knowledgeable experts cannot resolve at this stage. A mandatory notification and/or exclusion policy in a contact sport may be considered to be unfairly discriminatory, yet it may be equally unfair to expose potential opponents and team mates to a slightly increased risk of a life threatening transmissible disease without their knowledge and consent.

Now that a decade has passed since the Magic Johnson saga and there are no proven cases of sporting transmission 
of HIV, experts can feel safer in determining the risk of transmission to be "very low". But in that time, how many HIV positive athletes have continued to play contact sports, and if they have, do we have the follow up of all opponents and team mates to prove that none have been infected? The most important lesson from the Magic Johnson saga is that team mates and opponents did not feel comfortable playing against him, and I suspect that this aspect of the case has deterred the vast majority of HIV positive individuals from considering continuing participation in contact sports.

J Orchard

South Sydney Sports Medicine, 111 Anzac Parade, Kensington, NSW 2033, Australia; johnorchard@msn.com.au

\section{Clinical Evidence-Call for contributors}

Clinical Evidence is a regularly updated evidence-based journal available worldwide both as a paper version and on the internet. Clinical Evidence needs to recruit a number of new contributors. Contributors are healthcare professionals or epidemiologists with experience in evidence-based medicine and the ability to write in a concise and structured way.

\section{Areas for which we are currently seeking authors:}

- Child health: nocturnal enuresis

- Eye disorders: bacterial conjunctivitis

- Male health: prostate cancer (metastatic)

- Women's health: pre-menstrual syndrome; pyelonephritis in non-pregnant women However, we are always looking for others, so do not let this list discourage you.

Being a contributor involves:

- Selecting from a validated, screened search (performed by in-house Information Specialists) epidemiologically sound studies for inclusion.

- Documenting your decisions about which studies to include on an inclusion and exclusion form, which we keep on file.

- Writing the text to a highly structured template (about 1500-3000 words), using evidence from the final studies chosen, within 8-10 weeks of receiving the literature search.

- Working with Clinical Evidence editors to ensure that the final text meets epidemiological and style standards.

- Updating the text every six months using any new, sound evidence that becomes available. The Clinical Evidence in-house team will conduct the searches for contributors; your task is simply to filter out high quality studies and incorporate them in the existing text.

- To expand the topic to include a new question about once every 12-18 months.

If you would like to become a contributor for Clinical Evidence or require more information about what this involves please send your contact details and a copy of your CV, clearly stating the clinical area you are interested in, to Klara Brunnhuber (kbrunnhuber@ bmigroup.com).

\section{Call for peer reviewers}

Clinical Evidence also needs to recruit a number of new peer reviewers specifically with an interest in the clinical areas stated above, and also others related to general practice. Peer reviewers are healthcare professionals or epidemiologists with experience in evidence-based medicine. As a peer reviewer you would be asked for your views on the clinical relevance, validity, and accessibility of specific topics within the journal, and their usefulness to the intended audience (international generalists and healthcare professionals, possibly with limited statistical knowledge). Topics are usually 1500-3000 words in length and we would ask you to review between 2-5 topics per year. The peer review process takes place throughout the year, and our turnaround time for each review is ideally 10-14 days.

If you are interested in becoming a peer reviewer for Clinical Evidence, please complete the peer review questionnaire at www.clinicalevidence.com or contact Klara Brunnhuber (kbrunnhuber@bmigroup.com). 